\title{
Stress Responses of Peanut (Arachis hypogaea L.) Genotypes as Measured by Trigonelline Content after Exposure to UV-B Radiation
}

\author{
David Willmon', Amith R. Devireddy ${ }^{1,2}$, Madhuri Inupakutika1,2, Naveen Puppala3, \\ Youngkoo Cho $^{1 *}$
}

\author{
${ }^{1}$ Department of Biology, Eastern New Mexico University, Portales, NM, USA \\ ${ }^{2}$ Department of Biological Sciences, University of North Texas, Denton, TX, USA \\ ${ }^{3}$ Agricultural Science Center, New Mexico State University, Clovis, NM, USA \\ Email: *young.cho@enmu.edu
}

How to cite this paper: Willmon, D., Devireddy, A.R., Inupakutika, M., Puppala, N. and Cho, Y.K. (2017) Stress Responses of Peanut (Arachis hypogaea L.) Genotypes as Measured by Trigonelline Content after Exposure to UV-B Radiation. American Journal of Plant Sciences, 8, 998-1010.

https://doi.org/10.4236/ajps.2017.85066

Received: January 26, 2017

Accepted: April 17, 2017

Published: April 20, 2017

Copyright $\odot 2017$ by authors and Scientific Research Publishing Inc. This work is licensed under the Creative Commons Attribution International License (CC BY 4.0).

http://creativecommons.org/licenses/by/4.0/

(c) (i) Open Access

\begin{abstract}
UV-B radiation has been widely documented as a stressor for plants that can cause decreased biomass, reduction in photosynthesis, and oxidative stress. Trigonelline is a secondary metabolite that is biosynthesized in some plants in response to abiotic stress such as UV-B irradiation. The objectives of this study were to examine biochemical stress responses for peanut plants (Arachis hypogaea L.) of four different genotypes (Spanish, Valencia, Virginia, and Runner) after exposure at various lengths to UV-B radiation and to examine the alteration of trigonelline biosynthesis due to the age of the plants. Peanut plants from the genotypes were exposed to UV-B radiation at three exposure times $(60,120$, and $180 \mathrm{~min})$; plants from two growth stages, the flowering (R1) and early maturity (R7), were used. Significant positive correlations $\left(\mathrm{r}_{\mathrm{s}}\right.$ $0.29-0.74, P \leq 0.05)$ were found for trigonelline concentrations and UV-B exposure times. With longer exposure times of $180 \mathrm{~min}$ for plants at R7, trigonelline biosynthesis began as early as 10 days after treatment with 154.6 $\mu \mathrm{g} \cdot \mathrm{g}^{-1} \mathrm{DW}$ and remained or increased by up to $71.5 \mu \mathrm{g} \cdot \mathrm{g}^{-1} \mathrm{DW}(46.3 \%)$ throughout the sampling intervals $(10,20,30,40$, and 50 days after treatment) to a final value of $226.1 \mu \mathrm{g} \cdot \mathrm{g}^{-1} \mathrm{DW}$. All four genotypes at R7 exhibited trigonelline concentrations $47.3 \%$ to $52.4 \%$ ( 71.6 to $96.5 \mu \mathrm{g} \cdot \mathrm{g}^{-1} \mathrm{DW}$ ) higher than individuals at R1. Trigonelline biosynthesis at $\mathrm{R} 7$ was significantly $(P<0.05)$ affected by all levels of UV-B exposure, whereas trigonelline concentrations at R1 were significantly influenced $(P<0.05)$ by only the longer exposure times (120 and $180 \mathrm{~min}$ ). No statistically significant difference was found in trigonelline concentration among the four different genotypes. UV-B irradiation had the greatest effect on plants at R7 after 120 and $180 \mathrm{~min}$ of exposure, as 15 out of $20(75 \%)$ individuals had significantly higher $(P<0.05)$ trigonelline
\end{abstract}


concentrations.

\section{Keywords}

Abiotic Stress, Arachis hypogaea L., Trigonelline, UV-B

\section{Introduction}

Surface UV-B irradiance increased after the onset of ozone depletion in the 1970s but recent measurements show that efforts to reduce concentrations of ozone-depleting substances are viable; although this is promising, the future of surface UV-B irradiation is still uncertain [1] [2] [3]. UV-B is a biologically active portion of ultraviolet light with wavelengths between 280 and $315 \mathrm{~nm}$ [4]. Despite UV-B being a small component of sunlight, it can be damaging to many higher plant species and can cause mutations, damage to genetic material, reductions in photosynthetic activity, lower electron transfer rates, smaller shoot biomass, decreased leaf size, and reductions in chlorophyll content in leaves [5] [6] [7]. High doses of UV-B can cause oxidative stress in plants through the development of reactive oxygen species (ROS) which can cause damage to lipids and proteins [8]. UV-B radiation can affect photosynthesis by degrading core proteins (D1 and D2) of photosystem II, inactivating rubisco, altering stomatal conductance, and inducing changes in photosynthetic pigments [9]. Stress caused by UV-B radiation can have compounded effects when another stressor is present such as drought or nutrient deficiency [10] [11]. When a plant is stressed by drought accompanied by increased levels of UV-B radiation, the plant's natural defense capacity for oxidative stress can be compromised [12] [13].

Increased UV-B exposure led to an increase in UV-B-absorbing phenolic compounds and flavonoids in grape leaf tissue, which could be an important factor in UV-B acclimation [14]. Expression of genes such as COP1, which are regulated by the photoreceptor UVR8, and up-regulation of UV-absorbing secondary metabolites leads to acclimation to ambient UV-B [15] [16]. Herbaceous plants tend to produce more UV-B-absorbing compounds in response to elevated levels of UV-B in comparison to woody plants [17].

Although many negative effects of UV-B are known, low levels of UV-B radiation may also be relevant in the future as an exploitable regulator in horticulture [18]. UV-B can potentially be used to manipulate or increase levels of certain nutritional or pharmaceutically valuable phenolics, terpenoids, and alkaloids [19] [20]. The increase of medicinal plant substances in this way is not always considered a stress phenomenon, which means that low amounts of UV-B can still increase concentrations of the desired secondary metabolite without affecting plant growth or causing visible damage to the plant [21]. Lettuce (Lactuca sativa) that had been exposed to UV-B before being inoculated with mildew showed reduction in further sporation from the mildew as well as thickening of leaves, which suggested that UV-B might help increase plant disease tolerance 
[22].

Trigonelline is an alkaloid plant hormone which is a conjugate of nicotinic acid found primarily within roots, root exudates, seeds, and leaves in the legume (Fabaceae) family [23]. Trigonelline has been shown to be synthesized primarily from nicotinic acid produced by the degradation of nicotinamide adenine dinucleotide (NAD) in both mungbean (Phaseolus aureus) seedlings and coffee (Coffea arabica) fruits [24] [25]. Genetic analysis of soybean (Glycine max) has revealed that trigonelline biosynthesis is likely a polygenically inherited trait with differential expression dependent on environmental conditions [26] [27].

Trigonelline is known to function as a cell cycle regulator by promoting $\mathrm{G}_{2}$ arrest in both shoot and root meristems in response to various environmental stressors [28]. Trigonelline is also known to increase in concentrations within the leaves of plants in response to many abiotic stressors such as salt stress and drought stress [29] [30]. In this way, trigonelline functions as an osmoregulator to prevent water loss within plant cells. Increased levels of trigonelline also may be important as a response by plants undergoing oxidative stress: a build-up of reactive oxygen species and free radicals which lead to DNA strand breakage [31]. Because trigonelline concentrations increase in plant cells in response to oxidative stress, trigonelline can be used as a molecular marker to determine when a plant is undergoing oxidative stress [32]. The objectives of this study were to determine if any peanut genotype would be better adapted to UV-B rich environments, and to see how response to UV-B treatment is affected by plant age.

\section{Materials and Methods}

\subsection{Planting and Treatments}

Seeds from the following four genotypes were used: Val C (Valencia), ICGS 76 (Virginia), C 76 - 16 (Runner), and Chico (Spanish). The seeds were obtained from the New Mexico State University Agricultural Science Center in Clovis, NM. The seeds showed a $90 \%-100 \%$ germination rate according to standard seed germination tests carried out at NMSU. Scotts Hyponex potting soil (Hyponex Corporation, Marysville, $\mathrm{OH}$ ) was used, which has nitrogen, phosphate, and potash contents of $0.07 \%, 0.01 \%$, and $0.03 \%$, respectively. The soil was mixed with sand in a 1:1 mass ratio. Three seeds were sown into uniform, common $3.8 \mathrm{~L}$ pots. A random number generator was used to select one germinating seedling. Three different UV-B treatments were carried out separately at the beginning of the flowering stage (R1) and the early maturity stage (R7) during plant growth. The treatments consisted of 60,120 , and 180 min of UV-B exposure along with a control of no UV-B exposure. During the test period in 2013 and 2014, the experiment was run twice to test peanut plants at both $\mathrm{R} 1$ and at $\mathrm{R} 7$. The average daytime temperature in the greenhouse over the course of the study was $30.8^{\circ} \mathrm{C}$ $\pm 4.8^{\circ} \mathrm{C}$; the growth chamber was set to a daytime temperature of $30^{\circ} \mathrm{C}$. There were three replications for each treatment and genotype, giving a total of 48 plants per experiment (96 plants total). The plants were transferred to a growth 
chamber equipped with two $30 \mathrm{~W}$ UV-B bulbs for the treatments, which were carried out separately, 30 days after germination for plants within the R1 group and 90 days after germination for plants within the R7 group. Preliminary experiments were carried out to determine adequate treatment times, sampling intervals, and plant care regiments such as watering frequency. All plants were arranged in a randomized block design [33].

\subsection{Trigonelline Extraction and Analysis}

Leaf samples were taken ten days after the UV-B treatments and again at ten-day intervals until a total of four sampling events over 40 days occurred for plants at the flowering (R1) stage, and five sampling events over 50 days occurred for plants at the early maturity (R7) stage. Fresh weight and dry weight of the leaves were taken for the calculation of trigonelline concentrations. Trigonelline was purified by Dowex-1-OH and Dowex-50- $H^{+}$ion exchange chromatography [29]. The dried extracts were resuspended in $1 \mathrm{ml}$ of autoclaved water. Spectrophotometric analysis was made of the resuspended samples using a POLAR star Omega Plate Reader (Allmendgrün, Ortenberg, Germany) set at $264 \mathrm{~nm}$ to measure for trigonelline [34]. Trigonelline content was quantified using trigonelline standards (Sigma, St. Louis, MO, USA). Trigonelline concentrations were then calculated and converted into micrograms per gram dry weight $\left(\mu \mathrm{g} \cdot \mathrm{g}^{-1} \mathrm{DW}\right) \mathrm{using}$ a developed regression equation.

\subsection{Statistical Analysis}

Data were analyzed for significant interactions using the three-way mixed ANOVA in the General Linear Models procedure in IBM SPSS Statistics 20 (IBM Corp., Armonk, NY). Further analysis to determine simple main effects for genotypes and treatments was carried out with a Bonferroni correction for pairwise comparisons [35]. Due to significant differences also found between treatments, post hoc analysis was done with Bonferroni adjustment to determine where exactly the differences are; genotypes were combined and analyzed against a control so that the significant differences between treatments could be analyzed without being separated by genotype. The Spearman correlation coefficient $\left(\mathrm{r}_{s}\right)$ was also calculated to look for correlations within the data.

\section{Results}

\subsection{Interactions of Genotype with Other Variables on Trigonelline Concentrations Depending upon UV-B Exposure Times}

Analysis of variance was carried out for both flowering (R1) and early maturity (R7) plants (Table 1). Trigonelline concentrations of the four genotypes (Spanish, Virginia, Valencia, and Runner) were compared to controls within each treatment of 60,120 , and $180 \mathrm{~min}$ of UV-B exposure at each trigonelline sampling period $(10,20,30$, and 40 days for plants at $\mathrm{R} 1 ; 10,20,30$, 40, and 50 days for plants at R7). Analysis with a three-way mixed ANOVA showed no statistically significant interaction for a combined effect of treatments at R1 and R7 and 
Table 1. ANOVA with interactions for days after treatment (DAT), genotype, and treatment on trigonelline concentrations.

\begin{tabular}{cccccc}
\hline & df & Mean Square & F & Sig. & ${\text { Partial } \text { ta }^{2}}$ \\
\hline Flowering (R1) & & & & & \\
DAT (D) $\times$ Genotype (G) & 12 & $106456.76^{* *}$ & 3.816 & 0.000 & 0.263 \\
D $\times$ Treatment (T) & 12 & 40017.18 & 1.434 & 0.184 & 0.119 \\
G $\times$ T & 9 & 25518.99 & 1.107 & 0.386 & 0.237 \\
D $\times$ T $\times$ G & 36 & 23961.04 & 0.859 & 0.665 & 0.195 \\
Early Maturity (R7) & & & & & \\
DAT (D) $\times$ Genotype (G) & 12 & $375215.57^{* *}$ & 3.660 & 0.000 & 0.255 \\
D $\times$ Treatment (T) & 12 & $254536.56^{* *}$ & 2.483 & 0.006 & 0.189 \\
G $\times$ T & 9 & 387135.67 & 1.706 & 0.128 & 0.324 \\
D $\times$ T $\times$ G & 36 & 142975.37 & 1.395 & 0.092 & 0.282 \\
\hline
\end{tabular}

Significant differences at a level of $P<0.01$ are marked by ${ }^{* *}$.

genotypes over the sampling periods on trigonelline concentration, and no significant differences between genotypes due to the treatments. However, trigonelline concentrations were significantly $(P<0.01)$ altered over the 50 days of sampling after UV-B treatments in plants at R7 for the three different exposure times $(60,120$, and $180 \mathrm{~min})$. This significant interaction between days after treatment and UV-B treatments at R7 was not found in plants treated with UV$B$ at R1 (Table 1).

\subsection{Alteration of Trigonelline Concentrations at Flowering Stage (R1) and Early Maturity (R7) after UV-B Treatments}

Trigonelline concentrations at R1 for the Spanish genotype measured at 10 and 20 days after treatment (103.7 and $103.6 \mu \mathrm{g} \cdot \mathrm{g}^{-1} \mathrm{DW}$, respectively) were significantly higher $(P<0.05)$ as compared to the controls $\left(76.8\right.$ and $71.3 \mu \mathrm{g} \cdot \mathrm{g}^{-1} \mathrm{DW}$, respectively) with only $60 \mathrm{~min}$ of UV-B exposure. Significantly higher $(P<0.01)$ trigonelline concentrations were also found in the Spanish genotype at R1 as early as 20 days after 120 min of UV-B treatment with $109.7 \mu \mathrm{g} \cdot \mathrm{g}^{-1} \mathrm{DW}$ and 10 days after $180 \mathrm{~min}$ of UV-B treatment with $118.5 \mu \mathrm{g} \cdot \mathrm{g}^{-1} \mathrm{DW}$ (Figure 1). However, trigonelline concentrations at R1, 40 days after treatment, were $104.2 \mu \mathrm{g} \cdot \mathrm{g}^{-1}$ DW for Virginia with $60 \mathrm{~min}$ UV-B exposure and $100.9 \mu \mathrm{g} \cdot \mathrm{g}^{-1} \mathrm{DW}$ for Valencia with 120 min UV-B exposure, both of which are significantly higher $(P<0.01)$ as compared to their respective controls (Figure 1). With $180 \mathrm{~min}$ of UV-B exposure at $\mathrm{R} 1$, the Runner genotype was significantly higher $(P<0.05)$ at 20 and 40 days after treatment (101.1 and $97.8 \mu \mathrm{g} \cdot \mathrm{g}^{-1} \mathrm{DW}$, respectively) as compared to the controls (Figure 1). None of the genotypes treated at R1 exhibited significantly different trigonelline concentrations at 30 days after treatment as compared to the controls (Figure 1).

For plants at R7, trigonelline concentrations were significantly higher in six out of the 20 plants (30\%) treated with $60 \mathrm{~min}$ of UV-B exposure across all ge- 

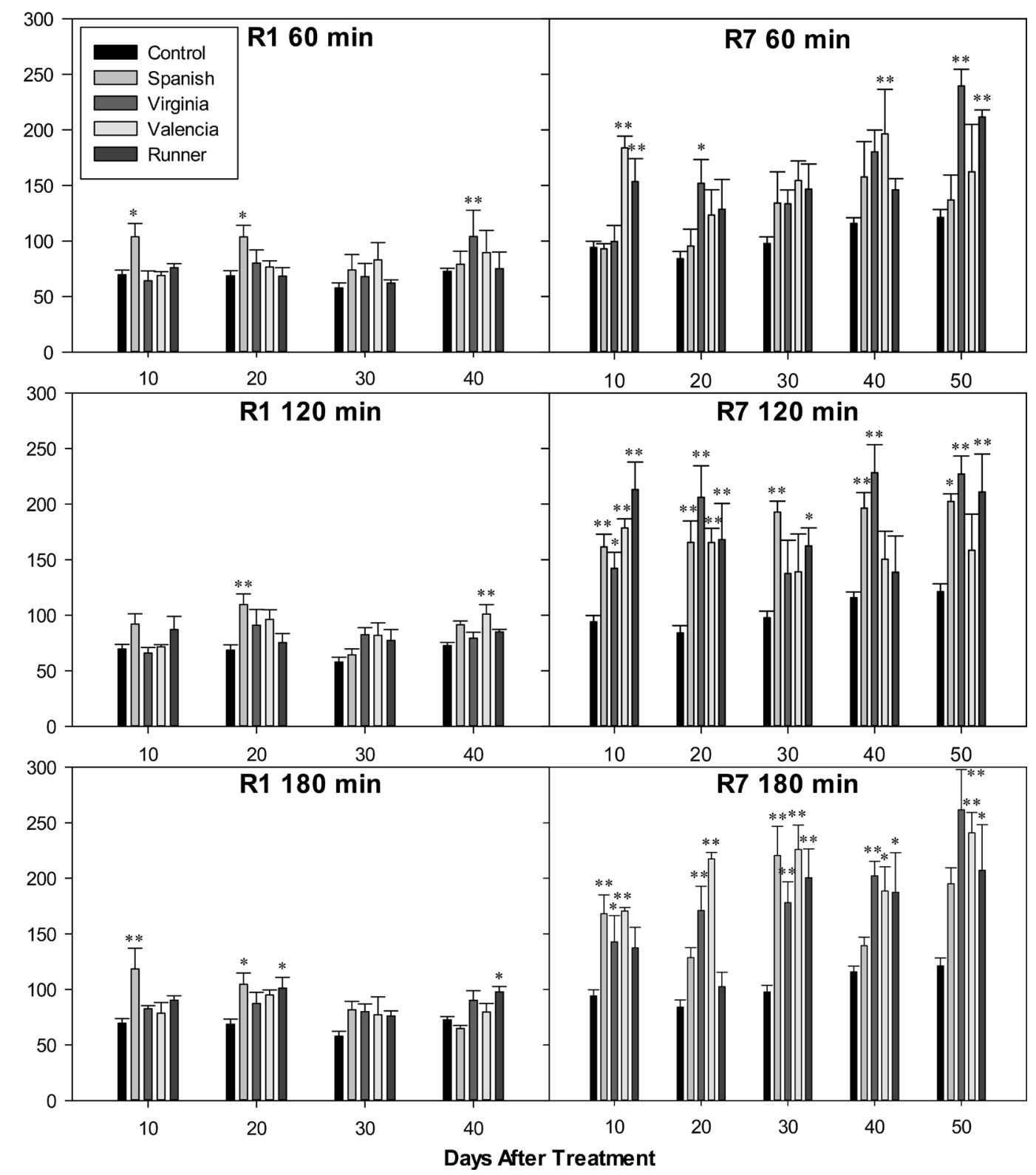

Figure 1. Trigonelline concentrations in $\mu \mathrm{g} \cdot \mathrm{g}^{-1} \mathrm{DW}$ at flowering (R1) and early maturity (R7) in Arachis hypogaea after 60,120, and 180 min of UV-B exposure. Treatment was administered to four market genotypes (Spanish, Virginia, Valencia, and Runner). Trigonelline concentrations were taken at 10, 20, 30, and 40 days after treatment for plants at R1 with an additional sampling period at 50 days for plants at R7. Significant differences at the level of $P<0.05$ and $P<0.01$ are marked by ${ }^{\star}$ and ${ }^{\star *}$ respectively as compared to the control.

notypes and sampling intervals; for plants treated with 120 and $180 \mathrm{~min}$ of UV-B exposure, a significant $(P<0.05)$ increase in trigonelline concentration was found in 15 out of the 20 plants (75\%) across all genotypes and sampling intervals (Figure 1). Virginia exhibited the highest levels of trigonelline at R7 across all UV-B exposure times at the end of the sampling period (50 days after treatment) with 239.5 at $60 \mathrm{~min}, 227.1$ at $120 \mathrm{~min}$, and $261.6 \mu \mathrm{g} \cdot \mathrm{g}^{-1} \mathrm{DW}$ at $180 \mathrm{~min}$ of exposure.

Genotypes were combined so that the effects of the different levels of UV-B 
treatments on trigonelline concentrations could be analyzed against a control (Figure 2). At R1, 60 min of UV-B exposure did not show any significant difference in trigonelline concentrations when compared to the control at any sampling interval. Trigonelline concentrations for the 120 minutes UV-B treatments were significantly different $(P \leq 0.05)$ at 20 and 30 days after treatment. The 180 minute UV-B treatments were significantly different $(P \leq 0.05)$ at 10,20 , and 30 days after treatment. Plants at R1 showed significantly higher levels of trigonelline $(P<0.05)$ only at the higher exposure times; the 60 minute treatments did not cause any significant increases at this growth stage when looking at the average response of all plants regardless of genotype. Trigonelline concentrations were highest for individuals at R1 20 days after treatment at 93.1 and $97.0 \mu \mathrm{g} \cdot \mathrm{g}^{-1}$ DW with 120 and 180 min of UV-B exposure respectively. At R7, the 60 minute UV-B treatment was significantly different $(P \leq 0.05)$ at $10,30,40$ and 50 days after treatment. The 120 minute and 180 minute UV-B treatments were both significantly different $(P<0.01)$ at all sampling intervals (Figure 2). Plants at R7 showed significantly higher levels $(P<0.05)$ of trigonelline as compared to the controls over the entirety of the 50-day sampling period. Plants at R7 exhibited trigonelline concentrations higher than their respective controls by $38.4 \mu \mathrm{g}^{-1} \mathrm{~g}^{-1}$ DW 10 days after 60 min of UV-B exposure to $105.1 \mu \mathrm{g} \cdot \mathrm{g}^{-1} \mathrm{DW} 50$ days after 180 min of UV-B exposure.

Spearman rank-order correlation coefficients $\left(r_{s}\right)$ were calculated for trigonelline concentrations associated with each treatment exposure time of control (no exposure), 60, 120, and $180 \mathrm{~min}$ of exposure at each sampling period (Table 2). There were positive correlations in all cases, varying in strength; the weakest positive correlation $\left(r_{s}=0.29\right)$ was found at $R 1,40$ days after treatments, while the strongest positive correlation $\left(r_{s}=0.74\right)$ was found at R7, 30 days after treatments.

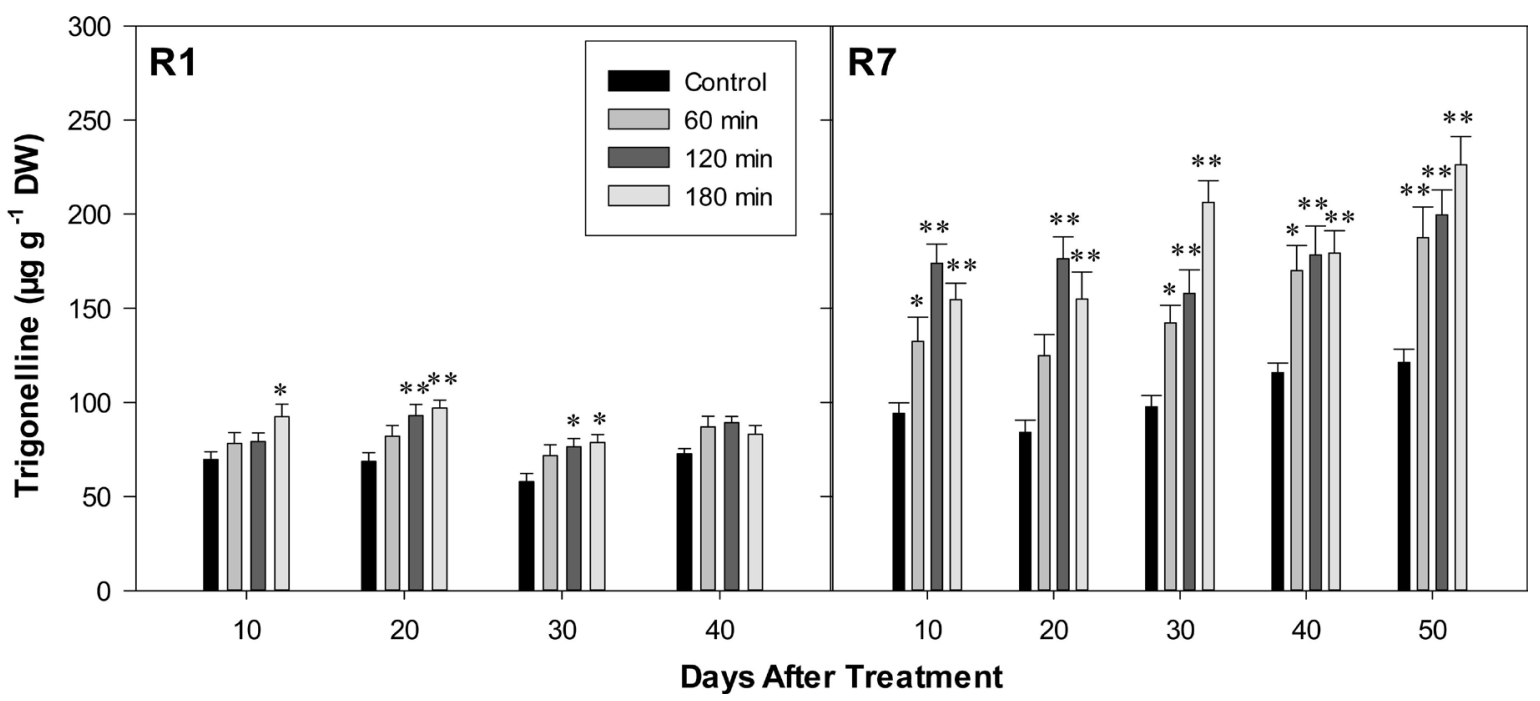

Figure 2. Trigonelline concentrations at flowering (R1) and early maturity (R7) in Arachis hypogaea after combining all genotypes. Three treatments of 60,120, and $180 \mathrm{~min}$ UV-B exposure along with a control were used. Trigonelline concentrations were taken at 10,20,30, and 40 days after treatment for plants at R1 with an additional sampling period at 50 days for plants at R7. Significant differences at the level of $P<0.05$ and $P<0.01$ are marked by ${ }^{*}$ and ${ }^{* *}$ respectively as compared to the control. 
Table 2. Spearman rank-order correlation coefficients and significance levels for trigonelline concentrations compared to treatment exposure levels $(0,60,120$, and $180 \mathrm{~min})$ at each sampling period.

\begin{tabular}{ccccc}
\hline Growth Stage & DAT $\dagger$ & DF & $\mathrm{r}_{\mathrm{s}}$ & Sig. \\
\hline Flowering (R1) & 10 & 46 & $0.39^{* *}$ & 0.006 \\
& 20 & 46 & $0.54^{* *}$ & 0.000 \\
Early Maturity (R7) & 30 & 46 & $0.43^{* *}$ & 0.003 \\
& 40 & 46 & $0.29^{*}$ & 0.048 \\
& 10 & 46 & $0.57^{\star *}$ & 0.000 \\
& 20 & 46 & $0.60^{\star *}$ & 0.000 \\
& 30 & 46 & $0.74^{\star *}$ & 0.000 \\
& 40 & 46 & $0.54^{* *}$ & 0.000 \\
& 50 & 46 & $0.61^{* *}$ & 0.000 \\
\hline
\end{tabular}

$\dagger$ Shown are days after treatment (DAT), degrees freedom (DF), the Spearman rank-order correlation coefficient $\left(\mathrm{r}_{\mathrm{s}}\right)$, and significance levels. Significant correlations at a level of $P<0.05$ and $P<0.01$ are marked by ${ }^{*}$ and $^{* *}$, respectively.

All positive correlations were statistically significant $(P \leq 0.05)$. As exposure time increases, trigonelline concentration increases as compared to the control when looking at all genotypes combined.

\section{Discussion}

\subsection{Comparing Stress Responses across Genotypes and Growth Stages after UV-B Exposure}

There was no evidence from this study to suggest that there is a significant difference in the trigonelline concentrations of the peanut genotypes Spanish, Virginia, Valencia, or Runner when compared to each other (Table 1). However, the genotypes used in this study did show significant differences $(P<0.05)$ when compared to the untreated control groups. This implies that peanut plants from the different genotypes employed in this study respond to UV-B exposure and the resulting oxidative stress similarly. It is not likely that one genotype would be significantly better adapted for UV-B rich environments or preferable for UV-B induced trigonelline biosynthesis over any other genotype. This may be due in part to low levels of genetic polymorphism ( $2.8 \%$ on average) between peanut genotypes and similarities with ancestral species [36]. However, trigonelline concentrations increased in all genotypes after irradiation by UV-B.

Individuals at R7 showed a greater increase in trigonelline concentration (by as much as $52.4 \%$ ) in response to UV-B irradiation and oxidative stress as compared to individuals at R1. This contrasts results from other studies where peanut plants (Arachis hypogaea L.) showed higher trigonelline concentrations at a younger growth stage (R4) as compared to an older growth stage (R8) under drought stress [37]. The same reduction of trigonelline content has been shown in other leguminous species such as soybean (Glycine max) and in non-leguminous species such as coffee (Coffea arabica) as the plants progress to maturity 
[30] [38]. However, in this study across all sampling periods, untreated individuals at R7 had 34.5\% more trigonelline on average than untreated individuals at $\mathrm{R} 1$, which gives a percent increase in natural trigonelline levels as the plants grow from a flowering stage to an early maturity stage. With $60 \mathrm{~min}$ of UV-B exposure, the average percent increase from R1 to R7 was 47.3\%; with 120 and 180 min of UV-B exposure, the average percent increase from R1 to R7 was $52.3 \%$ and $52.4 \%$ respectively. In this study, mature plants produced more trigonelline in response to oxidative stress than young plants; longer exposure times to UV-B resulted in a larger increase in trigonelline concentrations in plants at $\mathrm{R} 7$ in relation to plants at R1. Untreated plants at R7 produced significantly less trigonelline $(P<0.05)$ than plants treated with 60,120 , and 180 min UV-B exposure by $40.8 \%, 84.8 \%$, and $64.4 \%$, respectively just 10 days after UV-B treatments. Because of this, the observed increase of trigonelline in UV-B treated plants at R7 is likely due to the oxidative stress cause by UV-B exposure, and not to natural variation of trigonelline levels between growth stages.

A positive correlation $\left(r_{s}=0.29-0.74\right)$ was found between trigonelline concentrations and exposure time to UV-B radiation; as exposure time increased, trigonelline concentrations increased (Table 2). When looking at the overall data for combined genotypes, every sampling period in both growth stages showed statistically significant positive relationships $(P<0.05)$ between trigonelline concentrations and UV-B exposure times (Table 2). This is especially true for peanut plants at R7 compared to R1, as trigonelline levels were higher by $54.3 \mu \mathrm{g} \cdot \mathrm{g}^{-1}$ DW (41.0\% increase from R1 to R7) after just 10 days with only 60 min of UV-B exposure (Figure 2). To corroborate this finding, control plants at R7 (10 days after 60 min of UV-B exposure) produced significantly less $(P<0.05)$ trigonelline by $38.4 \mu \mathrm{g} \cdot \mathrm{g}^{-1} \mathrm{DW}$. The results of this study agree with previous studies on trigonelline and other secondary metabolites including alkaloids, plant phenolics, and flavonoids accumulating in plant leaves after exposure to UV-B radiation [19] [39]. Low levels of UV-B can be used as a regulator for inducing the production of secondary metabolites [40]. However, higher levels of trigonelline in peanut plants have been linked to lower seed yield [37]. Under stressful environmental conditions, optimizing trigonelline concentrations could lead to higher survivability of peanut plants with economically acceptable yield.

\subsection{Initiation of Trigonelline Synthesis in Peanut Genotypes after UV-B Treatments}

The four genotypes used in this study varied from each other in trigonelline concentrations over the course of the sampling periods after UV-B treatments, although the variation between genotypes was not statistically significant. Statistically significant levels of trigonelline biosynthesis at R1 were sporadic for the Virginia, Valencia, and Runner genotypes. The Spanish genotype showed an earlier response to UV-B exposure at R1 with a consistent significant rise $(P<$ $0.05)$ in trigonelline levels as early as 10 to 20 days after treatment for all three exposure times. Trigonelline levels at R7 varied across the sampling periods. 
However, all four genotypes showed an early response at R7, as soon as 10 days after treatment, with longer exposure times (120 and $180 \mathrm{~min}$ ) which increased or stayed relatively steady throughout the sampling periods (Figure 1). The overall results (Figure 1 and Figure 2 ) indicate that plants at R7 significantly ( $P$ $<0.05)$ responded to relatively short UV-B exposure (60 min), whereas individuals at R1 generally required longer UV-B exposure (120 and $180 \mathrm{~min}$ ). This infers that mature plants may start to biosynthesize trigonelline in response to UV-B earlier than younger plants.

\section{Conclusion}

The peanut genotypes Spanish, Virginia, Valencia, and Runner biosynthesize trigonelline in similar concentrations after irradiation with UV-B; it is unlikely that one genotype would have an advantage over the others in UV-B rich environments. Including a larger variety of peanut genotypes may elucidate differential stress responses not found in this study. Plant growth stages may play an important role in stress response as individuals at $\mathrm{R} 7$ had trigonelline concentrations $47.3 \%$ to $52.4 \%$ higher than individuals at R1. Plant age may be a more important variable than genotypic variability for the development of UV-B tolerant peanut crops [41]. Comparative transcriptomic study of UV-B responsive genes across multiple plant growth stages could clarify the differential expression in secondary metabolite biosynthesis due to plant age and could provide a stronger basis for the development of UV-B resistant crops.

\section{Acknowledgements}

This work was supported in part by research grants to Youngkoo Cho and Naveen Puppala from the Office of Academic Affairs, Eastern New Mexico University and in part by U.S. Department of Agriculture NIFA-Hatch funds provided to New Mexico Agricultural Experiment Station; New Mexico State University, New Mexico, USA, respectively.

\section{References}

[1] McKenzie, R.L., Aucamp, P.J., Bais, A.F., Björn, L.O. and Ilyas, M. (2007) Changes in biologically Active Ultraviolet Radiation Reaching the Earth's Surface. Photochemical and Photobiological Sciences, 6, 218-231. https://doi.org/10.1039/B700017K

[2] Bais, A.F., McKenzie, R.L., Bernhard, G., Aucamp, P.J., Ilyas, M., Madronich, S. and Tourpali, K. (2015) Ozone Depletion and Climate Change: Impacts on UV Radiation. Photochemical and Photobiological Sciences, 14, 19-52. https://doi.org/10.1039/C4PP90032D

[3] Bornman, J.F., Barnes, P.W., Robinson, S.A., Ballaré, C.L., Flint, S.D. and Caldwell, M.M. (2015) Solar Ultraviolet Radiation and Ozone Depletion-Driven Climate Change: Effects on Terrestrial Ecosystems. Photochemical and Photobiological Sciences, 14, 88-107. https://doi.org/10.1039/C4PP90034K

[4] Heijde, M. and Ulm, R. (2012) UV-B Photoreceptor-Mediated Signaling in Plants. Trends in Plant Science, 17, 230-237. https://doi.org/10.1016/j.tplants.2012.01.007

[5] Jansen, M.A.K., Gaba, V. and Greenberg, B.M. (1998) Higher Plants and UV-B Radiation: Balancing Damage, Repair and Acclimation. Trends in Plant Science, 3, 
131-135. https://doi.org/10.1016/S1360-1385(98)01215-1

[6] Rozema, J., Boelen, P. and Blokker, P. (2005) Depletion of Stratospheric Ozone over the Antarctic and Arctic: Responses of Plants of Polar Terrestrial Ecosystems to Enhanced UV-B, an Overview. Environmental Pollution, 137, 428-442.

[7] Surabhi, G.K., Reddy, K.R. and Singh, S.K. (2009) Photosynthesis, Fluorescence, Shoot Biomass and Seed Weight Responses of Three Cowpea (Vigna unguiculata (L.) Walp.) Cultivars with Contrasting Sensitivity to UV-B Radiation. Environmental and Experimental Botany, 66, 160-171.

[8] Yannarelli, G.G., Noriega, G.O., Battle, A. and Tomaro, M.L. (2006) Heme Oxygenase Up-Regulation in Ultraviolet-B Irradiated Soybean Plants Involves Reactive Oxygen Species. Planta, 244, 1154-1162. https://doi.org/10.1007/s00425-006-0297-x

[9] Kataria, S., Jajoo, A. and Guruprasad, K.N. (2014) Impact of Increasing UltravioletB (UV-B) Radiation on Photosynthetic Processes. Journal of Photochemistry and Photobiology B, 137, 55-66.

[10] Lau, T.S.L., Eno, E., Goldstein, G., Smith, C. and Christopher, D.A. (2006) Ambient Levels of UV-B in Hawaii Combined with Nutrient Deficiency Decrease Photosynthesis in Near-Isogenic Maize Lines Varying in Leaf Flavonoids: Flavonoids Decrease Photoinhibition in Plants Exposed to UV-B. Photosynthetica, 44, 394-403. https://doi.org/10.1007/s11099-006-0042-5

[11] Belnap, J., Phillips, S.L., Flint, S., Money, J. and Caldwell, M. (2008) Global Change and Biological Soil Crusts: Effects of Ultraviolet Augmentation under Altered Precipitation Regimes and Nitrogen Additions. Global Change Biology, 14, 670-686. https://doi.org/10.1111/j.1365-2486.2007.01509.x

[12] Doupis, G., Chartzoulakis, K. and Patakas, A. (2012) Differences in Antioxidant Mechanisms in Grapevines Subjected to Drought and Enhanced UV-B Radiation. Emirates Journal of Food and Agriculture, 24, 607-613.

[13] Reboredo, F. and Lidon, F.J.C. (2012) UV-B Radiation Effects on Terrestrial Plants -A Perspective. Emirates Journal of Food and Agriculture, 24, 502-509.

[14] Berli, F., Moreno, D., Piccoli, P., Hespanhol-Viana, L., Silva, M.F., Bressan-Smith, R., Cavagnaro, J.B. and Bottini, R. (2010) Abscisic Acid Is Involved in the Response of Grape (Vitis vinifera L.) cv. Malbec Leaf Tissues to Ultraviolet-B Radiation by Enhancing Ultraviolet-Absorbing Compounds, Antioxidant Enzymes, and Membrane Sterols. Plant, Cell \& Environment, 33, 1-10.

[15] Singh, S., Agrawal, S.B. and Agrawal, M. (2014) UVR8 Mediated Plant Protective Responses under Low UV-B Radiation Leading to Photosynthetic Acclimation. Journal of Photochemistry and Photobiology B, 137, 67-76.

[16] Wargent, J.J., Nelson, B.C.W., Mcghie, T.K. and Barnes, P.W. (2015) Acclimation to UV-B Radiation and Visible Light in Lactuca sativa Involves Up-Regulation of Photosynthetic Performance and Orchestration of Metabolome-Wide Responses. Plant, Cell \& Environment, 38, 929-940. https://doi.org/10.1111/pce.12392

[17] Li, F.R., Peng, S.L., Chen, B.M. and Hou, Y.P. (2010) A Meta-Analysis of the Responses of Woody and Herbaceous Plants to Elevated Ultraviolet-B Radiation. Acta Oecologica, 36, 1-9.

[18] Jansen, M.A.K., Hideg, E. and Lidon, F.J.C. (2012) UV-B Radiation: "When Does the Stressor Cause Stress?” Emirates Journal of Food and Agriculture, 24.

[19] Jansen, M.A.K., Hectors, K., O’Brien, N.M., Guisez, Y. and Potters, G. (2008) Plant Stress and Human Health: Do Human Consumers Benefit from UV-B Acclimated Crops? Plant Science, 175, 449-458.

[20] Schreiner, M., Mewis, I., Huyskens-Keil, S., O’Briend, M.A. and Krumbein, A. 
(2012) UV-B Induced Secondary Plant Metabolites-Potential Benefits for Plant and Human Health. Critical Reviews in Plant Sciences, 31, 229-240. https://doi.org/10.1080/07352689.2012.664979

[21] Zhang, W.J. and Björn, L.O. (2009) The Effect of Ultraviolet Radiation on the Accumulation of Medicinal Compounds in Plants. Fitoterapia, 80, 207-218.

[22] Wargent, J.J., Taylor, A. and Paul, N.D. (2006) UV Supplementation for Growth Regulation and Disease Control. Acta Horticulturae, 711, 333-338. https://doi.org/10.17660/ActaHortic.2006.711.45

[23] Evans, L.S. and Tramontano, W.A. (1984) Trigonelline and Promotion of Cell Arrest in $\mathrm{G}_{2}$ of Various Legumes. Phytochemistry, 23, 1837-1840.

[24] Zheng, X.Q., Matsui, A. and Ashihara, H. (2008) Biosynthesis of Trigonelline from Nicotinate Mononucleotide in Mungbean Seedlings. Phytochemistry, 69, 390-395.

[25] Ashihara, H., Deng, W. and Nagai, C. (2011) Trigonelline Biosynthesis and the Pyridine Nucleotide Cycle in Coffea arabica Fruits: Metabolic Fate of [Carboxyl ${ }^{-14} \mathrm{C}$ ] Nicotinic Acid Riboside. Phytochemistry Letters, 4, 235-239.

[26] Cho, Y., Njiti, V.N., Chen, X., Triwatayakorn, K., Kassem, M.A., Meksem, K., Lightfoot, D.A. and Wood, A.J. (2002) Quantitative Trait Loci Associated with Foliar Trigonelline Accumulation in Glycine max L. Journal of Biomedicine and Biotechnology, 2, 151-157. https://doi.org/10.1155/S1110724302204039

[27] Kassem, M.A., Shultz, J., Meksem, K., Cho, Y., Wood, A.J., Iqbal, M.J. and Lightfoot, D.A. (2006) An Updated "Essex" by "Forrest" Linkage Map and First Composite Interval Map of QTL Underlying Six Soybean Traits. Theoretical and Applied Genetics, 113, 1015-1026. https://doi.org/10.1007/s00122-006-0361-8

[28] Evans, L.S., Almeida, M.S., Lynn, D.G. and Nakanishi, N. (1979) Chemical Characterization of a Hormone That Promotes Cell Arrest in $\mathrm{G}_{2}$ in Complete Tissues. Science, 203, 1122-1123. https://doi.org/10.1126/science.203.4385.1122

[29] Cho, Y., Lightfoot, D. and Wood, A.J. (1999) Trigonelline Concentrations in Salt Stressed Leaves of Cultivated Glycine max. Phytochemistry, 52, 1235-1238.

[30] Cho, Y., Njiti, V.N., Chen, X., Lightfoot, D.A. and Wood, A.J. (2003) Trigonelline Concentration in Field-Grown Soybean in Response to Irrigation. Biologia Plantarum, 46, 405-410. https://doi.org/10.1023/A:1024390522259

[31] Berglund, T. (1994) Nicotinamide, a Missing Link in the Early Stress Response in Eukaryotic Cells: A Hypothesis with Special Reference to Oxidative Stress in Plants. FEBS Letters, 351, 145-149. https://doi.org/10.1016/0014-5793(94)00850-7

[32] Kalbin, G., Ohlsson, A.B., Berglund, T., Rydström, J. and Strid, Å. (1997) UV-B Radiation Causes Changes in Intracellular Levels of Nicotinamide, Trigonelline and Glutathione in Pisum sativum Leaves. Phyton (Horn, Austria), 37, 115-124.

[33] Vorasoot, N., Songsri, P., Akkasaeng, C., Jogloy, S. and Patanothai, A. (2003) Effect of Water Stress on Yield and Agronomic Characters of Peanut (Arachis hypogaea L.). Songklanakarin Journal of Science and Technology, 25, 283-288.

[34] Yuyama, S. and Suzuki, T. (1985) Isolation and Identification of $N^{1}$-Methylnicotinic Acid (Trigonelline) from Rat Urine. Journal of Nutritional Science and Vitaminology, 31, 157-167. https://doi.org/10.3177/jnsv.31.157

[35] Dohleman, F.G., Heaton, E.A., Arundale, R.A. and Long, S.P. (2012) Seasonal Dynamics of Above- and Below-Ground Biomass and Nitrogen Partitioning in Miscanthus $\times$ giganteus and Panicum virgatum across Three Growing Seasons. Global Change Biology Bioenergy, 4, 534-544. https://doi.org/10.1111/j.1757-1707.2011.01153.x

[36] Bertioli, D.J., Cannon, S.B., Froenicke, L., Huang, G., Farmer, A.D., Cannon, E.K.S., 
Liu, X., Gao, D., Clevenger, J., Dash, S., Ren, L., Moretzsohn, M.C., Shirasawa, K., Huang, W., Vidigal, B., Abernathy, B., Chu, Y., Niederhuth, C.E., Umale, P., Araújo, A.C.G., Kozik, A., Kim, K.D., Burow, M.D., Varshney, R.K., Wang, X., Zhang, X., Barkley, N., Guimaräes, P.M., Isobe, S., Guo, B., Liao, B., Stalker, H.T., Schmitz, R.J., Scheffler, B.E., Leal-Bertioli, S.C.M., Xun, X., Jackson, S.A., Michelmore, R. and Ozias-Akins, P. (2016) The Genome Sequences of Arachis duranesis and Arachis ipaensis, the Diploid Ancestors of Cultivated Peanut. Nature Genetics, 48, 438-446. https://doi.org/10.1038/ng.3517

[37] Cho, Y., Kodjoe, E., Puppala, N. and Wood, A.J. (2011) Reduced Trigonelline Accumulation Due to Rhyzobial Activity Improves Grain Yield in Peanut (Arachis hypogaea L.). Acta Agriculturae Scandinavica, Section B, 61, 395-403. https://doi.org/10.1080/09064710.2010.494614

[38] Ashihara, H. and Watanabe, S. (2014) Accumulation and Function of Trigonelline in Non-Leguminous Plants. Natural Product Communications, 9, 795-798.

[39] Nascimento, L.B.S., Leal-Costa, M.V., Menezes, E.A., Lopes, V.R., Muzitano, M.F., Costa, S.S. and Tavares, E.S. (2015) Ultraviolet-B Radiation Effects on Phenolic Profile and Flavonoid Content of Kalanchoe pinnata. Journal of Photochemistry and Photobiology B: Biology, 148, 73-81.

[40] Sakalauskaitè, J., Viskelis, P., Dambrauskienè, E., Sakalauskienè, S., Samuolienè, G., Brazaityte், A., Duchovskis, P. and Urbonavičienè, D. (2013) The Effects of Different UV-B Radiation Intensities on Morphological and Biochemical Characteristics in Ocimum basilicum L. Journal of the Science of Food and Agriculture, 93, 1266 1271. https://doi.org/10.1002/jsfa.5879

[41] Morales, L.O., Brosché, M., Vainonen, J., Jenkins, G.I., Wargent, J.J., Sipari, N., Strid, Å., Lindfors, A.V., Tegelberg, R. and Aphalo, P.J. (2013) Multiple Roles for UV RESISTANCE LOCUS8 in Regulating Gene Expression and Metabolite Accumulation in Arabidopsis under Solar Ultraviolet Radiation. Plant Physiology, 161, 744759. https://doi.org/10.1104/pp.112.211375

Submit or recommend next manuscript to SCIRP and we will provide best service for you:

Accepting pre-submission inquiries through Email, Facebook, LinkedIn, Twitter, etc. A wide selection of journals (inclusive of 9 subjects, more than 200 journals)

Providing 24-hour high-quality service

User-friendly online submission system

Fair and swift peer-review system

Efficient typesetting and proofreading procedure

Display of the result of downloads and visits, as well as the number of cited articles

Maximum dissemination of your research work

Submit your manuscript at: http://papersubmission.scirp.org/

Or contact ajps@scirp.org 